\title{
Selective Cleavage of SCO by Transition Metal Complexes
}

\author{
Tekle Setargew
}

\section{Abstract}

Computational and experimental research has shown that small multiply bonded molecules can be activated and cleaved by three coordinate transition metal complexes. The activation and selective cleavage of bonds in SCO was investigated in this study by computational methods using Density Functional Theory. Metal amide complexes $\left(\mathrm{ML}_{3}\right.$, where $\mathrm{M}=\mathrm{Mo}, \mathrm{Re}, \mathrm{Ta}$, and $\left.\mathrm{L}=\mathrm{NH}_{2}\right)$ were used in combinations of $\mathrm{Mo} / \mathrm{Mo}, \mathrm{Re} / \mathrm{Ta}$, and $\mathrm{Ta} / \mathrm{Ta}$ in order to investigate the possibility of achieving selective cleavage of SCO. For the Mo/Mo and $\mathrm{Ta} / \mathrm{Ta}$ systems, the cleavage step for either system was not found to be favourable on the basis of enthalpy considerations, but was calculated to be favourable if entropy effects were included, on the basis of the resulting free energy reaction profile. Different selectivity was observed for each system, with S-C scission favoured for the Mo/Mo case, and C-O scission favoured for the $\mathrm{Ta} / \mathrm{Ta}$ case. In the Re/Ta system, cleavage of the SCO molecule is thermodynamically favourable, but no selectivity is observed. However, given that no barrier was found for cleavage of the S-C bond, in contrast to the observation of a relatively small barrier for cleavage of the $\mathrm{C}-\mathrm{O}$ bond, it is inferred that $\mathrm{S}-\mathrm{C}$ scission may be favoured on mechanistic grounds.

\section{Introduction}

Interest in small molecule activation initially comes from the necessity of achieving cleavage of the $\mathrm{N}-\mathrm{N}$ triple bond for nitrogen fixation. $\mathrm{N}_{2}$ is converted to ammonia by breaking this bond; industrially this is currently achieved by using temperatures of approximately $500 \mathrm{~K}$ and pressures around 500atm in the Bosch-Haber Process [1]. Very large amounts of energy are used during the Bosch-Haber Process in order to produce ammonia from atmospheric $\mathrm{N}_{2}$ which is an important material used for production of fertilisers and explosives [1, 2].

Other methods to achieve the fixation of $\mathrm{N}_{2}$ under milder conditions have been investigated. Some methods involve using transition metal complexes to lower the activation energy of the reaction. This is achieved by binding a metal to 
$\mathrm{N}_{2}$ which then weakens and activates the bond between the nitrogen atoms by some amount depending on the metal and ligands used in the complex. Laplaza and Cummins, in 1995, were able to synthesise a three coordinate Molybdenum complex, Mo(NRAr) $)_{3}$, where $\mathrm{R}$ is $\mathrm{C}\left(\mathrm{CD}_{3}\right)_{2} \mathrm{CH}_{3}$ and $\mathrm{Ar}$ is $3,5-\mathrm{C}_{6} \mathrm{H}_{3}\left(\mathrm{CH}_{3}\right)_{2}$, stabilised by the steric bulk of its ligands, which was then able to cause scission of the N-N triple bond under mild conditions [3]. Since then interest in using transition metal complexes to activate small molecules such as $\mathrm{N}_{2}$ has grown, and this problem has been widely investigated using computational methods as well [2].

The activation of diatomic small molecules with strong multiple bonds, such as $\mathrm{N}_{2}, \mathrm{NO}, \mathrm{CN}^{-}$and $\mathrm{CO}$, using transition metal complexes, has been investigated in previous studies utilising the Density Functional Theory [4-9]. Density Functional Theory is a quantum mechanical modelling method which is commonly used in chemistry and physics to investigate electronic structure and properties of systems of atoms and molecules. This relies on using functionals of electron density to simplify calculations that involve many electrons.

The factor that drives the reaction has been hypothesised to be the stability of the product metal complexes relative to the reactants. This stability is derived from the strength of the bond of the metal to the fragment atom from the small molecule [7]. It has been shown that the extent of activation of the small molecule bond is increased for heavier elements within a group and earlier elements within a period, as the heavier and earlier transition metals form stronger bonds to fragment atoms such as $\mathrm{C}, \mathrm{N}$, and $\mathrm{O}$, due to the combination of more dilated $\mathrm{d}$ orbitals and more favourable energy match between energy levels [7].

The activation and cleavage of the bond in the $\mathrm{N}_{2}$ molecule is achieved through back donation of electrons to the $\pi^{*}$ orbital [8]. In order to accomplish this, the metal must have the appropriate $\mathrm{d}$ orbital configuration and be able to bind strongly to the molecule [8,9]. A small molecule that is a greater $\pi$ acceptor is more easily cleaved. The choice of ligands is also important in achieving transfer of electron density to the small molecule [4].

Experimental ligands are too big for calculations used in studies of this kind and therefore, ligands such as $\mathrm{NH}_{2}$ and $\mathrm{OH}$ have to be used. While these do not reproduce steric effects of the experimental ligands, they do have the appropriate similar electronic effects which are more significant in causing activation and cleavage of the small molecule bond [4], and allow calculations to become far less computationally demanding.

After in depth study of the activation of many strong multiply bonded diatomic molecules, attention has turned to the activation and cleavage of a variety of triatomic molecules, such as $\mathrm{N}_{2} \mathrm{O}$ [10] and $\mathrm{CS}_{2}$ [11]. In the case of $\mathrm{N}_{2} \mathrm{O}, \mathrm{a} \mathrm{MoL}_{3}$ complex binding to both ends of the molecule was able to cause scission of the 
$\mathrm{N}-\mathrm{N}$ bond without breaking the $\mathrm{N}-\mathrm{O}$ bond, the weaker of the two bonds in the molecule. Selectivity of cleavage was then reversed by using $\mathrm{MoL}_{3}$ binding to the $\mathrm{N}-\mathrm{N}$ end and $\mathrm{NbL}_{3}$ binding to the $\mathrm{N}-\mathrm{O}$ end. These results were computationally rationalised on the basis of the stability of the products produced [12].

The purpose of this study was to extend the investigations on the selective cleavage of unsymmetric triatomic molecules by focusing on carbonyl sulphide, SCO. While SCO does not have as large industrial significance as $\mathrm{N}_{2}$ it is an important molecule to study because there has been relatively little computational work done on the selective cleavage of unsymmetric triatomic molecules. This investigation also focused on whether it is possible to achieve selective cleavage of the $\mathrm{C}-\mathrm{O}$ bond instead of the significantly weaker S-C bond, which is an important result. As it is similar to $\mathrm{CS}_{2}$, an analogous approach was used in order to investigate selective cleavage of the S-C and C-O bonds in SCO [11].

\section{Computational Details}

Two main methods are used in computational chemistry to perform calculations: methods involving electron density such as the Density Functional Theory and methods that involve wave functions, such as Hartree-Fock and electron correlation approaches. In the latter the calculations become much longer and more complicated if they involve atoms with large numbers of electrons, such as calculations involving transition metals, so in this investigation Density Functional approaches were used [13].

All density functional calculations were carried out using the Amsterdam Density Functional (ADF 2010) package [14-16]. A Generalized Gradient Approximation (GGA) functional consisting of the exchange and correlation expressions proposed by Becke [17] and Perdew [18] respectively, was utilised. Basis sets of the all-electron type and triple-zeta quality - including one polarization function (TZP) - were employed [14-16].

As the non-relativistic Schrodinger Wave equation does not accurately describe heavy atoms, in which relativistic effects become important for electrons close to the nucleus, these effects were taken into account by using the Zero Order Regular Approximation (ZORA) [19-21].

The calculations were performed under solvation effects incorporated by using the Conductor-like Screening Model (COSMO) [22], with toluene as the solvent. This model allows calculations to more accurately represent the experimental systems. 
The ANU Undergraduate Research Journal

Calculations were performed in a spin-unrestricted manner using default convergence parameters, whose values are $10^{-3}$ hartree for energy, $10^{-3}$ hartree/ angstrom for gradients, and 4.0 for the integration accuracy.

\subsection{Bonding Energy Analysis}

Bonding interactions were investigated by means of an energy decomposition analysis $[23,24]$ that employs a fragment approach to the molecular structure of a chemical system. In this approach, the decomposition of the total bonding energy $\left(E_{B}\right)$ is given as,

$\mathrm{E}_{\mathrm{B}}=\mathrm{E}_{\mathrm{E}}+\mathrm{E}_{\mathrm{P}}+\mathrm{E}_{\mathrm{O}}$

where $E_{E^{\prime}} E_{P^{\prime}}$ and $E_{O}$ are, respectively, the electrostatic interaction, Pauli repulsion, and orbital interaction terms. A detailed description of the physical significance of these terms has been given by Bickelhaupt and Baerends [25].

The bonding energy $\left(\mathrm{E}_{\mathrm{B}}\right)$ can be considered a measure of the instantaneous interactions between the fragments in the molecule, but does not represent the bond dissociation energy $\left(E_{D}\right)$ which is defined as,

$\mathrm{E}_{\mathrm{D}}=\mathrm{E}_{\mathrm{B}}+\mathrm{E}_{\mathrm{F}}$

and contains, in addition to the bonding energy, a contribution $\left(\mathrm{E}_{\mathrm{F}}\right)$ arising from the fragment preparation process. This process can be described as the energy associated with the transformation of the fragments from their equilibrium geometric and electronic states into their "intrinsic" geometric and electronic states in the molecule.

The electrostatic $\left(\mathrm{E}_{\mathrm{E}}\right)$ term is calculated from the superposition of the unperturbed fragment densities at the molecular geometry, and corresponds to the classical electrostatic effects associated with coulombic attraction and repulsion. The electrostatic contribution is generally dominated by the nucleuselectron attractions and therefore has a stabilizing influence. The Pauli $\left(\mathrm{E}_{\mathrm{p}}\right)$ term arises from the requirement that electronic antisymmetry conditions be satisfied and is associated with repulsive four-electron two-orbital interactions and therefore has a destabilizing effect. The orbital interaction $\left(\mathrm{E}_{\mathrm{O}}\right)$ term represents a stabilizing factor originating from the relaxation of the molecular system due to the mixing of occupied and unoccupied orbitals, and can involve electron-pair bonding, charge-transfer or donor-acceptor interactions, and polarization. 


\section{Results and Discussion}

\subsection{SCO Molecule}

The geometry of the SCO molecule was calculated and is given in Figure 1 and Table 1 below. The frequencies of the molecule were also calculated and are displayed in Table 2.

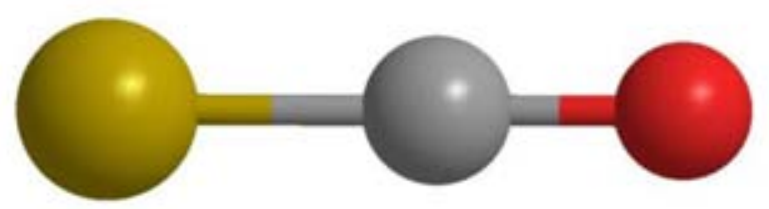

Figure 1: Structure of the SCO molecule: S (left), C (middle) and $\mathrm{O}$ (right).

Table 1: Comparison of Geometric Parameters for the SCO molecule. Calculated in the Gas Phase, Solvent Phase and Experimentally Determined.

\begin{tabular}{|l|c|c|}
\hline & \multicolumn{2}{|c|}{ Bond Length (pm) } \\
\hline & S-C & C-O \\
\hline Gas Phase & 157 & 117 \\
\hline Solvent Phase & 157 & 117 \\
\hline Experimental $[26,27]$ & 156 & 116 \\
\hline
\end{tabular}

Table 2: Comparison of Vibrational Frequency results for the SCO molecule. Calculated in the Gas Phase, Solvent Phase and Experimentally Determined.

\begin{tabular}{|l|l|l|}
\hline Frequency $\left(\mathrm{cm}^{-1}\right)$ & Solvent Phase & Experimental [28] \\
\hline Gas Phase & 1996 & 2062 \\
\hline 2033 & 853 & 859 \\
\hline 855 & 493 & 521 \\
\hline 498 & & \\
\hline
\end{tabular}

As can be seen in Figure 1 and Table 1, the experimental geometry of SCO matches very closely to the calculated geometry in both the gas and solvent phases. The frequencies calculated for the SCO are overall in reasonable agreement with those determined experimentally. The bond strength of the S-C and C-O bonds were also calculated in the solvent phase to be $366 \mathrm{~kJ} / \mathrm{mol}$ for S-C and 752 $\mathrm{kJ} / \mathrm{mol}$ for the $\mathrm{C}-\mathrm{O}$ bond, with a difference of $386 \mathrm{~kJ} / \mathrm{mol}$. The experimentally determined bond strengths are given as $305 \mathrm{~kJ} / \mathrm{mol}$ for $\mathrm{S}-\mathrm{C}$ and $668 \mathrm{~kJ} / \mathrm{mol}$ for C-O [29]. While individual bond strengths do not match well with those 
calculated, the difference between the experimental bond strengths, $363 \mathrm{~kJ} / \mathrm{mol}$ is close to the difference in calculated bond strengths. The molecular orbitals of SCO were also calculated and are given in Figure 2 below.

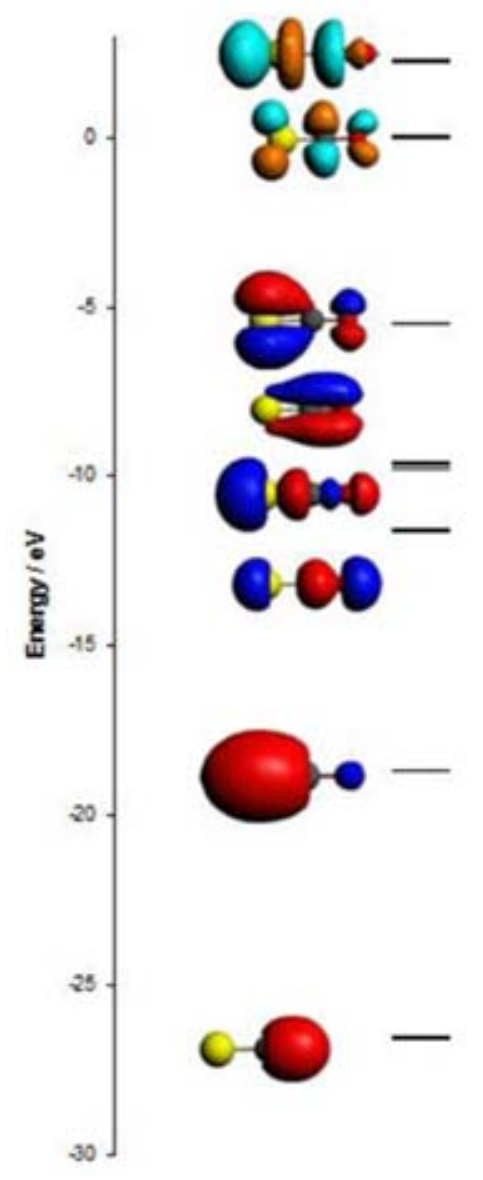

Figure 2: Calculated Molecular Orbitals for SCO: S (left), C (middle) and O (right). Energy of each orbital is given relative to the LUMO.

Based on the character of the HOMO and LUMO it can be seen that the sulphur end of the molecule should be more reactive than the oxygen end. The lowest unoccupied molecular orbital is observed to have a $\pi$ antibonding character, so by introducing electrons to this orbital from the metal atoms the bonds in the molecule should be weakened significantly. 


\subsection{Reaction Energetics}

The mechanism for the cleavage reaction of SCO is based on previous studies, in particular the investigation of bond scission in $\mathrm{N}_{2} \mathrm{O}$ [10] and $\mathrm{CS}_{2}$ [11]. The reaction is as follows:

Reactants $\rightarrow$ Encounter Complex $\rightarrow$ Dinuclear Species $\rightarrow$ Products

The structures of the reactants and products involved in the reaction are well established from previous investigations [4-11]. Several structures for the encounter complex and dinuclear species were investigated for each system.

Based on the experimental systems involving molybdenum complexes used in other studies, $\mathrm{Mo}\left(\mathrm{NH}_{2}\right)_{3}$ complexes were used in initial calculations investigating activation and cleavage of SCO. The thermodynamic profile for the Mo/Mo system is shown in Figure 3 and the results from a calculation of the barrier to S-C scission are shown in Figure 4.

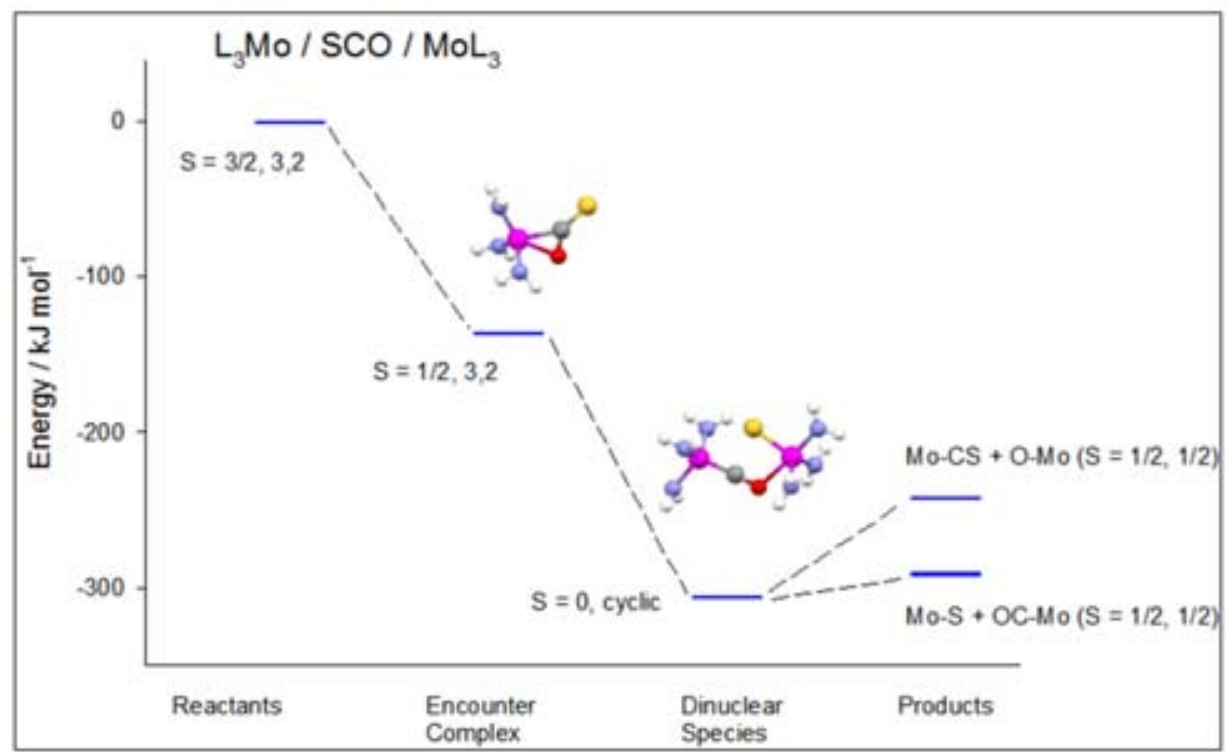

Figure 3: Energy profile for the Mo/Mo system including the structures of the encounter complex and dinuclear species. $1=\mathrm{H}, 2=\mathrm{N}, 3=\mathrm{Mo}, 4=0$, $5=\mathrm{C}$ and $\mathbf{6}=\mathrm{S}$. 


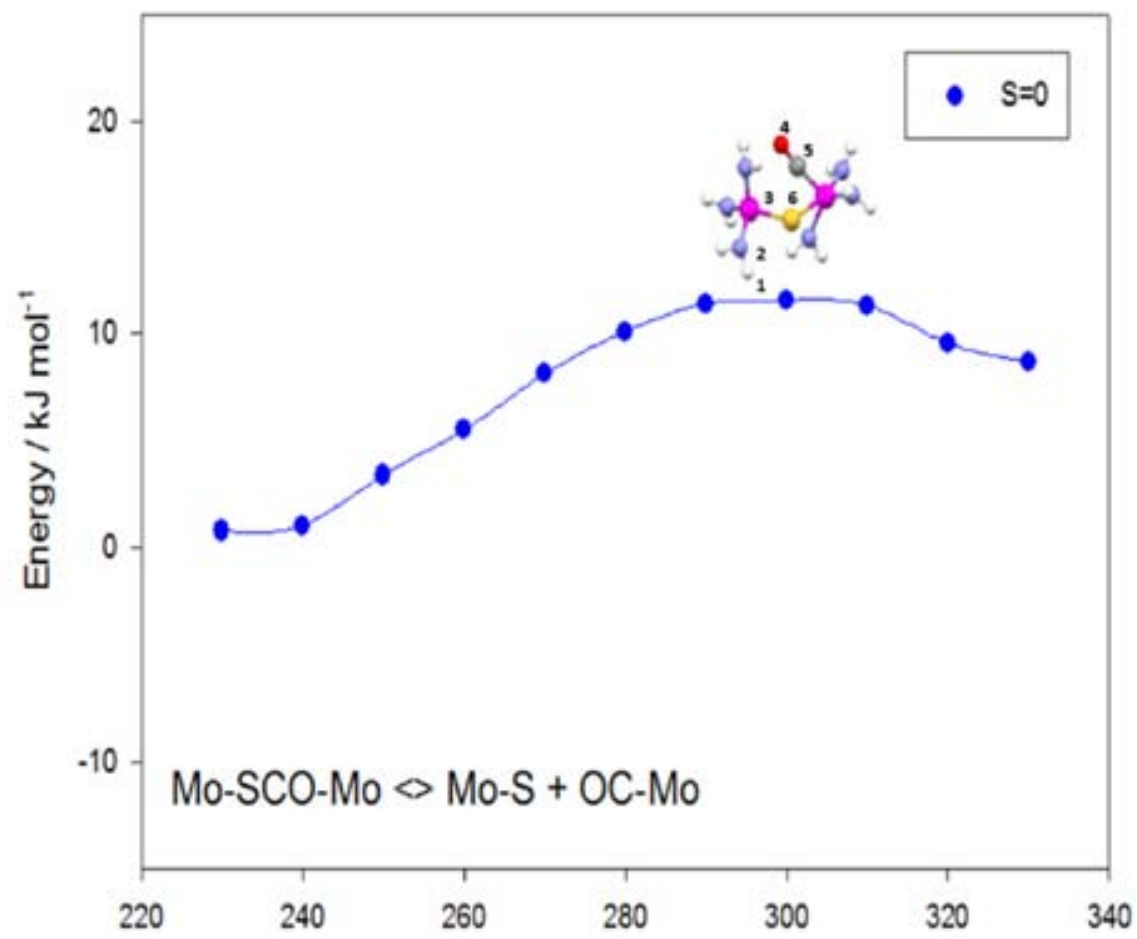

Figure 4: Energy barrier calculated for the breaking of the S-C bond. Structure of transition state is shown, where $1=\mathrm{H}, 2=\mathrm{N}, 3=\mathrm{Mo}, 4=0$, $5=\mathrm{C}$ and $\mathbf{6}=\mathrm{S}$.

It is clear from this profile that the cleavage of either bond is thermodynamically unfavourable. The cleavage of the $\mathrm{S}-\mathrm{C}$ bond is however significantly more favourable than cleavage of the $\mathrm{C}-\mathrm{O}$ bond, preferred by $45 \mathrm{~kJ} / \mathrm{mol}$.

The selectivity of SCO bond cleavage can be rationalised on the basis of the competing effects of product stability and reactant bond strength. The total bonding energy of the products formed from $\mathrm{C}-\mathrm{O}$ scission is more favourable (Table 3) as Mo forms a particularly strong bond with the $\mathrm{O}$ fragment. However, this overall difference in product stability is not sufficient to compensate for the much larger dissociation energy of the $\mathrm{C}-\mathrm{O}$ relative to $\mathrm{S}-\mathrm{C}$ bonds, and $\mathrm{S}-\mathrm{C}$ scission is thus energetically more facile.

Table 3: Bonding energy of respective products from cleavage of SCO in the Mo/Mo system.

\begin{tabular}{|c|c|c|}
\hline \multicolumn{2}{|c|}{ Intrinsic Bonding Energy of Products $(\mathrm{kJ} / \mathrm{mol})$} & Total $(\mathrm{kJ} / \mathrm{mol})$ \\
\hline Mo-CS & O-Mo & -1257 \\
\hline-530 & -727 & \\
\hline Mo-CO & S-Mo & -905 \\
\hline-390 & -515 & \\
\hline
\end{tabular}


Two particularly significant molecular orbitals of the products are shown in Figure 5.

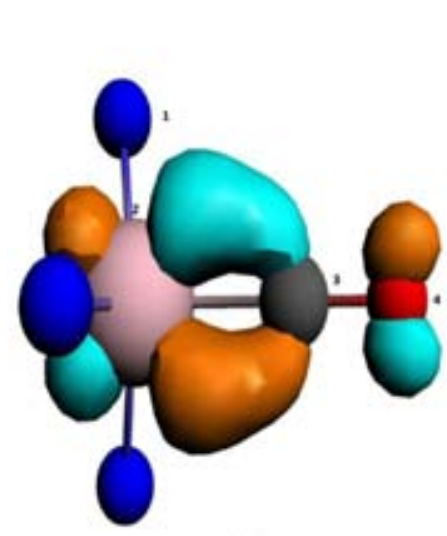

(a)

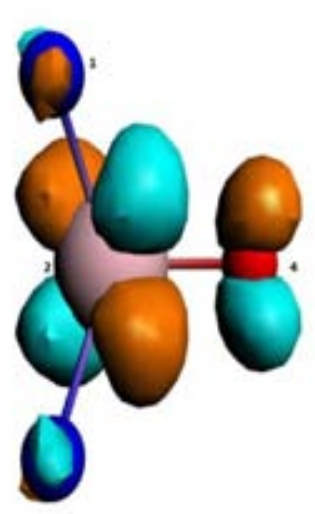

(b)

Figure 5: Calculated HOMO for L3Mo-CO produced by cleavage of S-C and $\mathrm{C}-\mathrm{O}$ bonds. (a) Calculated HOMO for L3Mo-CO, produced by cleavage of S-C bond. (b) Calculated HOMO for L3Mo-O, produced by cleavage of $\mathrm{C}-\mathrm{O}$ bond. Where $1=\mathrm{L}=\mathrm{NH} 2,2=\mathrm{Mo}, 3=\mathrm{C}, 4=\mathrm{O}$ (largely similar properties are found for L3Mo-CS, and L3Mo-S).

Some unfavourable orbital occupancy patterns result from the use of Mo atoms with a formal $\mathrm{d}^{3}$ configuration, namely, the HOMO of $\mathrm{L}_{3} \mathrm{Mo}-\mathrm{CO}$ and $\mathrm{L}_{3} \mathrm{Mo}-\mathrm{CS}$ contains 3 instead of 4 electrons, thereby reducing the bonding character of this interaction, whereas in $\mathrm{L}_{3} \mathrm{Mo}-\mathrm{O}$ and $\mathrm{L}_{3} \mathrm{Mo}-\mathrm{S}$, an antibonding orbital is occupied leading to additional destabilization of the products. These observations are consistent with the predicted unfavourable character of the $\mathrm{S}-\mathrm{C}$ or $\mathrm{C}-\mathrm{O}$ cleavage steps.

Following this result, a system using Rhenium and Tantalum complexes was predicted to lead to more favourable thermodynamic properties for the cleavage step, as these metals would stabilise the products of $\mathrm{S}-\mathrm{C}$ and $\mathrm{C}-\mathrm{O}$ bond scission. This is due to the $\mathrm{d}^{4}$ electron configuration of the Re atom, which fully occupies the bonding orbital when binding to $\mathrm{CS}$ or $\mathrm{CO}$, and the $\mathrm{d}^{2}$ electron configuration of the Ta atom, which avoids occupation of the antibonding orbital when binding to $\mathrm{O}$ or $\mathrm{S}$. The use of the heavier Re and Ta atoms, which should form stronger bonds than their lighter counterparts in the $4 \mathrm{~d}$ transition series, should also contribute to increasing the thermodynamic driving force for the cleavage step.

The energy profile for the Re/Ta system is given in Figure 6 and the calculation results of energy barriers for the cleavage of the $\mathrm{S}-\mathrm{C}$ and $\mathrm{C}-\mathrm{O}$ bonds are given in Figure 7. 




Figure 6: Energy profile for the Re/Ta system. This includes the structure of the encounter complex and dinuclear species. $1=\mathrm{H}, 2=\mathrm{N}, 3=\mathrm{Re}, 4=0$, $5=\mathrm{C}, 6=\mathrm{S}$ and $7=\mathrm{Ta}$.

From the energy profile in Figure 6, cleavage of the $\mathrm{C}-\mathrm{O}$ bond is energetically favourable by $101 \mathrm{~kJ} / \mathrm{mol}$ and cleavage of the S-C bond is favourable by $100 \mathrm{~kJ} / \mathrm{mol}$, therefore, no selectivity is predicted on the basis of reaction thermochemistry. However, there is a barrier of $27 \mathrm{~kJ} / \mathrm{mol}$ for the cleavage of the $\mathrm{C}-\mathrm{O}$ bond, and no such barrier exists for the cleavage of the $\mathrm{S}-\mathrm{C}$ bond. This suggests that while each set of products may be similar in energy, the S-C scission is likely to be preferred as this will take place spontaneously.

The failure to observe bond cleavage selectivity was confirmed by an analysis of the bonding energy of the respective products S-C and C-O scission (Table 4).

Table 4: Bonding energy of respective products from cleavage of SCO in the $\mathrm{Re} / \mathrm{Ta}$ system.

\begin{tabular}{|c|c|c|}
\hline \multicolumn{2}{|c|}{ Intrinsic Bond Energy of Products $(\mathrm{kJ} / \mathrm{mol})$} & Total $(\mathrm{kJ} / \mathrm{mol})$ \\
\hline Re-CS & $\mathrm{O}-\mathrm{Ta}$ & -1701 \\
\hline-693 & -1008 & \\
\hline $\mathrm{Re}-\mathrm{CO}$ & $\mathrm{S}-\mathrm{Ta}$ & -1313 \\
\hline-561 & -752 & \\
\hline
\end{tabular}




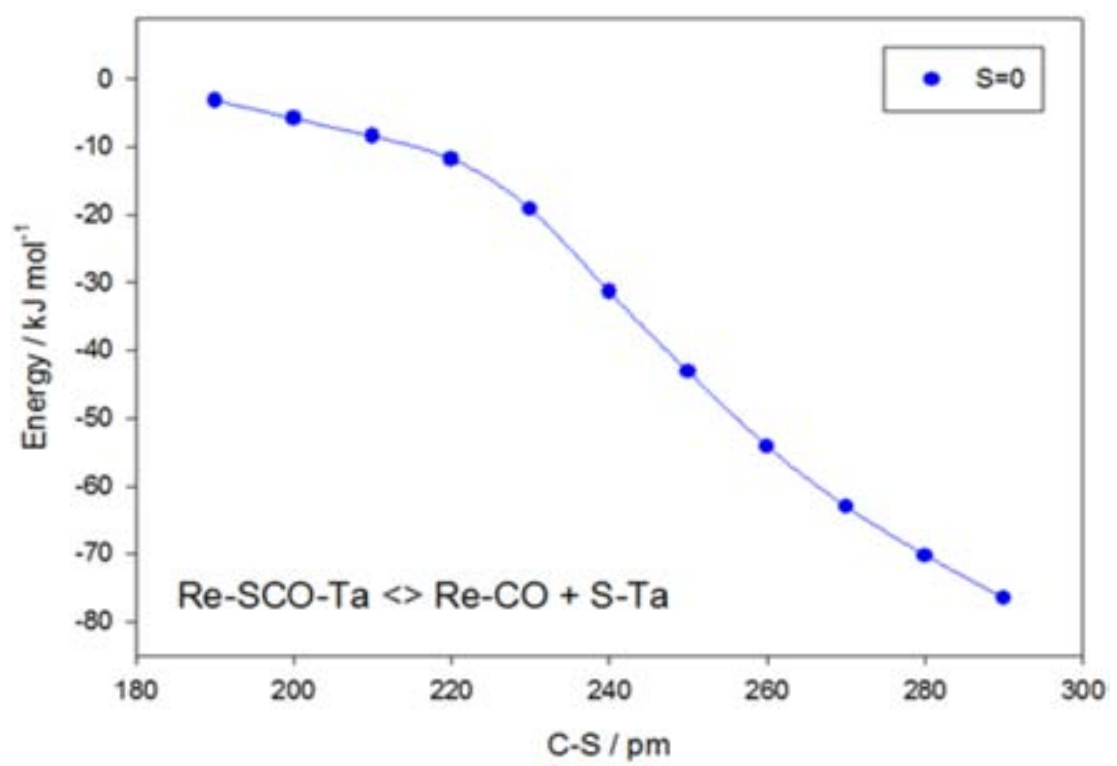

(a)

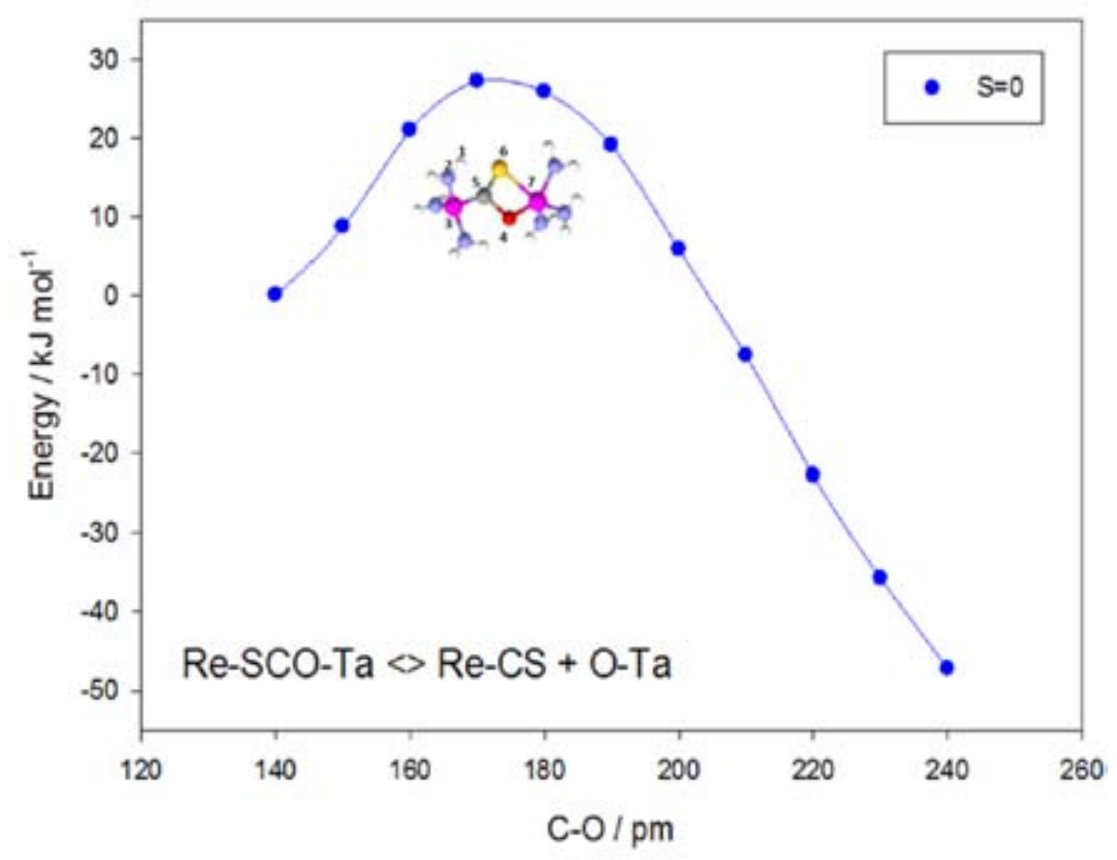

(b)

Figure 7: Energy barrier calculations for Re/Ta system. (a) cleavage of the S-C bond, and (b) cleavage of the $\mathrm{C}-\mathrm{O}$ bond, including transition state structure. Where $1=\mathrm{H}, 2=\mathrm{N}, 3=\mathrm{Re}, 4=0,5=\mathrm{C}, 6=\mathrm{S}$ and $7=\mathrm{Ta}$. 
Based on the bonding energy of the products, it can be seen that cleavage of the $\mathrm{C}-\mathrm{O}$ bond is favoured, thermodynamically driven by the increased stability of the products, most notably, the large Ta-O bond strength. The stability of the products determined from bonding energy suggests cleavage of the $\mathrm{C}-\mathrm{O}$ bond, however the energy required to break that bond counteracts the extra stability of forming these products, and this is why there is no preference for breaking $\mathrm{C}-\mathrm{O}$ based on the reaction profile (stability effect is $388 \mathrm{~kJ} / \mathrm{mol}$ in favour of C-O scission products counteracted by $386 \mathrm{~kJ} / \mathrm{mol}$ in favour of breaking the weaker S-C bond).

Based on the bonding energy calculations for the Re/Ta system, a Ta/Ta system was also investigated in order to explore the possibility of achieving selective cleavage of the $\mathrm{C}-\mathrm{O}$ bond.

$\mathrm{The} \mathrm{Ta} / \mathrm{Ta}$ system would be better to use from an experimental perspective as it can more accurately model a possible experimental system, as Tantalum is more viable to use than Rhenium, and has in fact been used in previous studies [30].

The other experimental advantage that $\mathrm{Ta} / \mathrm{Ta}$ would have is that only one metal is being used and there does not need to be as much consideration into the formation of the encounter complex.

The energy profile for the Ta/Ta system is given in Figure 8 .

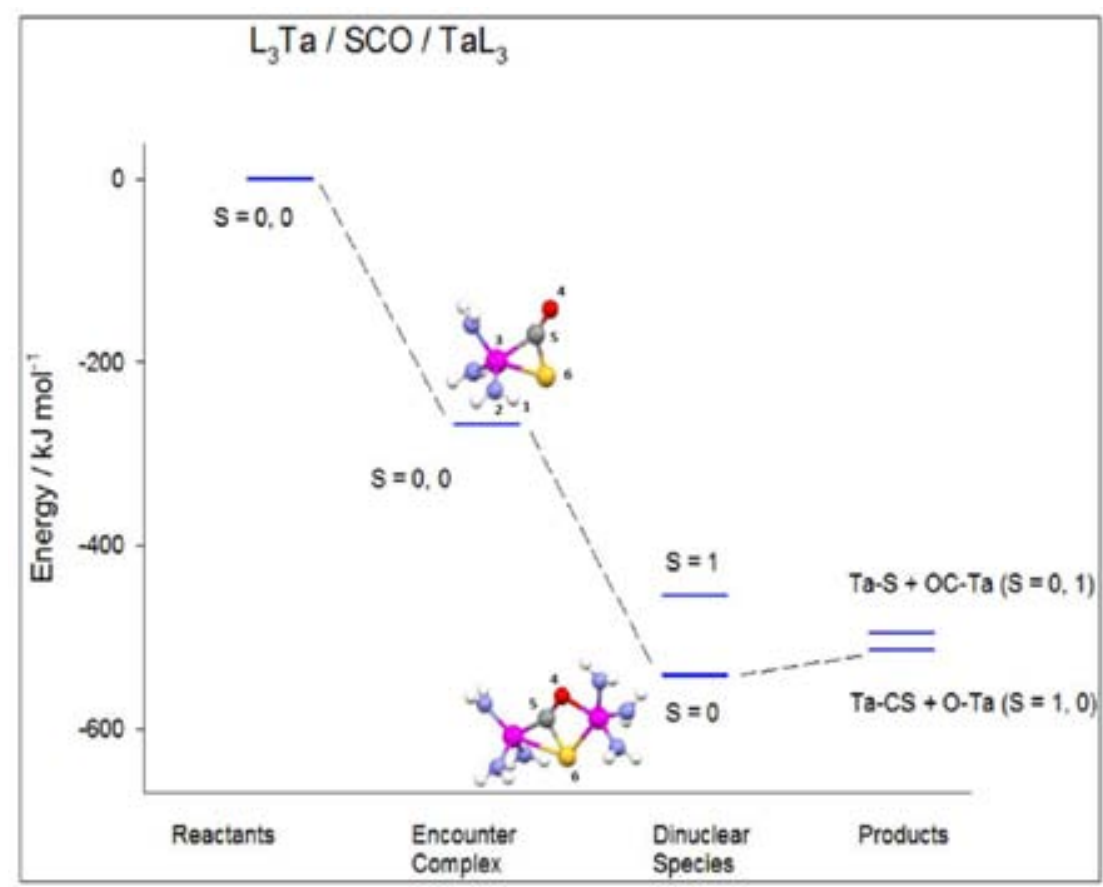

Figure 8: Energy profile for the $\mathrm{Ta} / \mathrm{Ta}$ system. This includes structures of 
Figure 8 shows that cleavage of the $\mathrm{C}-\mathrm{O}$ bond is preferred over cleavage of the $\mathrm{S}-\mathrm{C}$ bond by $16 \mathrm{~kJ} / \mathrm{mol}$, although the process is still unfavourable based on the stability of the dinuclear species relative to products. Barrier and transition states for the breaking of the $\mathrm{C}-\mathrm{O}$ bond could not be obtained for the $\mathrm{Ta} / \mathrm{Ta}$ system due to severe convergence issues.

The effects of entropy in the cleavage step of the reaction were estimated for each system. It is expected that these effects can be significant, as the cleavage step involves going from a single molecule system to a two molecule system, which leads to an increase in entropy in the cleavage step of the reaction. The enthalpy and free energy of the cleavage step for each system are given in Table 5.

Table 5: Enthalpy and free energy for the cleavage step of Mo/Mo, Re/Ta, and $\mathrm{Ta} / \mathrm{Ta}$ systems.

\begin{tabular}{|c|c|c|c|}
\hline System & Products & $\begin{array}{c}\Delta \mathrm{E}(\mathrm{kJ} / \mathrm{mol})-\text { including } \\
\text { Zero Point Correction }\end{array}$ & $\Delta \mathrm{G}(\mathrm{kJ} / \mathrm{mol})$ \\
\hline $\mathrm{Mo} / \mathrm{Mo}$ & Mo-CO $+\mathrm{S}-\mathrm{Mo}$ & 7 & -48 \\
\hline & Mo-CS $+\mathrm{O}-\mathrm{Mo}$ & 52 & -7 \\
\hline $\mathrm{Re} / \mathrm{Ta}$ & $\mathrm{Re}-\mathrm{CO}+\mathrm{S}-\mathrm{Ta}$ & -102 & -167 \\
\hline & $\mathrm{Re}-\mathrm{CS}+\mathrm{O}-\mathrm{Ta}$ & -106 & -164 \\
\hline $\mathrm{Ta} / \mathrm{Ta}$ & $\mathrm{Ta}-\mathrm{CO}+\mathrm{S}-\mathrm{Ta}$ & 28 & -37 \\
\hline & $\mathrm{Ta}-\mathrm{CS}+\mathrm{O}-\mathrm{Ta}$ & 12 & -49 \\
\hline
\end{tabular}

It is clear from Table 5 that cleavage of the dinuclear species to form the products is favourable for the Mo/Mo and Ta/Ta systems when entropic effects are taken into consideration and selectivity is displayed in both of these systems. Mo/Mo shows a preference of $41 \mathrm{~kJ} / \mathrm{mol}$ for S-C breaking, and $\mathrm{Ta} / \mathrm{Ta}$ has the opposite selectivity, with cleavage of $\mathrm{C}-\mathrm{O}$ bond favoured by $12 \mathrm{~kJ} / \mathrm{mol}$. The cleavage of SCO by the Re/Ta system is favourable on the basis of both enthalpy and free energy results, but there is no clear selectivity for this system.

\section{Conclusion}

The selective cleavage of the SCO molecule by three coordinate transition metal complexes was investigated computationally using Density Functional Theory methods. Three systems were studied, Mo/Mo, Ta/Ta and Re/Ta.

Based on electronic structure considerations, the Re/Ta system was expected to lead to the most favourable overall results, and although it did produce the most thermodynamically favoured cleavage of SCO, there was no clear selectivity for S-C or C-O bond scission. However, cleavage of S-C bond may be preferably observed on the basis that the $\mathrm{S}-\mathrm{C}$ scission step is predicted to occur spontaneously, whereas a barrier to $\mathrm{C}-\mathrm{O}$ scission does appear to exist. 
Cleavage of SCO in both the Mo/Mo and Ta/Ta systems was found to be unfavourable on the basis of initial enthalpy results, but subsequent inclusion of entropy effects indicates that the bond scission step should be favoured by overall free energy change. Cleavage can in principle be selectively achieved using these two complexes. Mo/Mo selectively cleaved the S-C bond, preferred by $41 \mathrm{~kJ} / \mathrm{mol}$, and Ta/Ta selectively cleaved the $\mathrm{C}-\mathrm{O}$ bond, which was favoured by $12 \mathrm{~kJ} / \mathrm{mol}$.

\section{Related Issues and Future Work}

It is always important to consider the possible uncertainties in any experiment, however calculations performed using the Amsterdam Density Functional package do not provide such information. It is still believed that the results obtained from these calculations are accurate and reliable, in particular that the differences in energy between sets of products are large compared to the possible uncertainties.

While the choice to use $\mathrm{NH}_{2}$ ligands in this study was made to reduce computational time and gain a general understanding of the mechanism of the selective cleavage of SCO, the simplicity of using this model does have some drawbacks. In particular the choice of such simple ligands does not take into account steric factors that play an important role in the real system. The $\mathrm{NH}_{2}$ ligands are also free to rotate; this is not possible in the real system, which uses much larger ligands. This study has provided a basis for further work on the selective cleavage of SCO by transition metal complexes, which will involve more realistic ligand sets.

\section{References}

[1] J. R. Postgate, Nitrogen Fixation, Cambridge University Press, Cambridge, 1998.

[2] G. J. Christian, A Computational Study of Small Molecule Activation inTransition Metal Complexes, Doctor of Philosophy Thesis, The Australian National University, 2006.

[3] C. E. Laplaza, C. C. Cummins, Science, 1995, 268, 861.

[4] G. J. Christian, J. Driver, R. Stranger, Faraday Discuss., 2003, 124, 331-341.

[5] G. J. Christian, R. Stranger, B. F. Yates, C. C. Cummins, Dalton Trans., 2008, 3, 338-344. 
[6] G. J. Christian, R. Stranger, S. Petrie, B. F. Yates, C. C. Cummins, Chem. Eur. J., 2007, 13, 4264-4272.

[7] G. J. Christian, R. Stranger, B. F. Yates, Inorg. Chem., 2006, 45, 17, 6851-6859.

[8] G. Cavigliasso, G. Christian, R. Stranger, B. F. Yates, Dalton Trans., 2009, 6, 956-964.

[9] G. Cavigliasso, G. Christian, R. Stranger, B. F. Yates, Dalton Trans., 2011, 9, 7327-7339.

[10] J. F. Cherry, A. R. Johnson, L. M. Baraldo, Y. Tsai, C. C. Cummins, S. V. Kryatov, E. V. Rybak-Akimova, K. B. Capps, C. D. Hoff, C. M. Haar, S. P. Nolan, J. Am. Chem. Soc., 2001, 123, 7271-7286.

[11] A. Ariafard, N. J. Brookes, R. Stranger, B. F. Yates, J. Am. Chem. Soc., 2008, 130, 36, 11928-11938.

[12] A. Criddle, Selective Cleavage of Nitrous Oxide with Three-Coordinate Metal Complexes, Bachelor of Science Project, The Australian National University, 2010 .

[13] F. Jensen, Introduction to Computational Chemistry, Wiley, England, 2007.

[14] C. Fonseca Guerra, O. Visser, J.G. Snijders, G. te Velde \& E.J. Baerends (E. Clementi and C. Corongiu, eds.), in: Methods and Techniques for Computational Chemistry, p. 303-395, STEF, Cagliari, 1995.

[15] C. Fonseca Guerra, J.G. Snijders, G. te Velde, E.J. Baerends, Theor. Chem. Acc., 1998, 99, 391.

[16] G. te Velde, F.M. Bickelhaupt, S.J.A. van Gisbergen, C. Fonseca Guerra, E.J. Baerends, J.G. Snijders, T. Ziegler, J. Comput. Chem., 2001, 22, 931.

[17] A.D. Becke, Phys. Rev. A, 1988, 38, 3098.

[18] J.P. Perdew, Phys. Rev. B, 1986, 33, 8822.

[19] E. van Lenthe, E.J. Baerends, J.G. Snijders, J. Chem. Phys., 1993, 99, 4597.

[20] E. van Lenthe, E J. Baerends, J.G. Snijders, J. Chem. Phys., 1994, 101, 9783.

[21] E. van Lenthe, A.E. Ehlers, E.J. Baerends, J. Chem. Phys., 1999, 110, 8943.

[22] C.C. Pye, T. Ziegler, Theor. Chem. Acc., 1999, 101, 396.

[23] T. Ziegler, A. Rauk, Inorg. Chem., 1979, 18, 1558.

[24] T. Ziegler, A. Rauk, Inorg. Chem., 1979, 18, 1755. 
The ANU Undergraduate Research Journal

[25] F.M. Bickelhaupt, E.J. Baerends, Rev. Comput. Chem., 2000, 15, 1.

[26] J.K.G Watson, J. Molecular Spectroscopy, 1973, 48, 479-502.

[27] A.G. Maki, D.R. Johnson, J. Molecular Spectroscopy, 1973, 47, 226-233.

[28] M. J. Tubergen, R. J. Lavrich, J. W. McCarger, J. Chem. Ed., 2000, 77, 16371639.

[29] Y-R. Luo, Comprehensive handbook of chemical bond energies, Taylor and Francis, Florida, 2007.

[30] M. D. Fryzuk, Acc. of Chem. Res., 2009, 42, 127-133. 